\title{
Aberrant Expression of Mitotic Cdc2/Cyclin B1 Kinase in Degenerating Neurons of Alzheimer's Disease Brain
}

\author{
Inez Vincent, Gregory Jicha, Michelle Rosado, and Dennis W. Dickson \\ Departments of Pathology and Neurology, Albert Einstein College of Medicine, Bronx, New York 10461
}

\begin{abstract}
We have shown previously that M-phase phospho-epitopes accumulate in neuronal tau proteins incorporated into the hallmark neurofibrillary tangles (NFT) of Alzheimer's disease (AD). In $\mathrm{M}$ phase, the epitopes are produced by cdc2/cyclin B1 kinase by a highly conserved mechanism believed to be quiescent in terminally differentiated neurons of adult brain. To determine whether an M-phase mechanism is possible in $A D$ neurons, we first investigated the presence of cdc2 and cyclin $B 1$ in $A D$. Both proteins were enriched in neurons with NFT and in neurons susceptible to NFT. An antibody specific for catalytically active cdc2 stained numerous NFT-containing neurons in $A D$ but did not react with normal neurons. Double-labeling studies showed that active cdc2 and cyclin B1 coexist in AD neurons and co-localize with $A D$-specific mitotic phosphoepitopes. Mitotic kinase purified from $A D$ and normal brain,
\end{abstract}

using the yeast p13suc1 protein as affinity ligand, showed higher histone $\mathrm{H} 1$ phosphorylation activity in AD. Accordingly, the levels of cdc2 and cyclin B1 in p13suc1 fractions from AD were higher than normal. Consistent with a physiological relationship between NFT and mitotic kinase, NFT proteins copurified with and became phosphorylated by the p13suc1bound kinase in vitro. Furthermore, cdc2/cyclin B1 is the only one of several proline-directed kinases that created the TG/MC mitotic phospho-epitopes in recombinant tau in vitro. These findings suggest that aberrantly reexpressed cdc2/cyclin B1 in NFT-bearing neurons in $A D$ brain contributes to the generation of M-phase phospho-epitopes in NFT.

Key words: cdc2; cyclin B; p13suc1; neuronal degeneration; Alzheimer's disease; neurofibrillary tangle
Marked neuronal loss in Alzheimer's disease (AD) is often preceded by deposition of neurofibrillary tangles (NFT) that contain hyperphosphorylated proteinaceous aggregates called paired helical filaments (PHF) (for review, see Terry et al., 1994) (Trojanowski et al., 1993). Although these lesions have been studied for decades, little is known about the biochemical mechanisms that produce them. We recently presented evidence that certain NFT-specific monoclonal antibodies (i.e., the TG and MC series) recognize phospho-epitopes that are of a mitotic nature, displaying a temporally restricted pattern of appearance during $M$ phase in a variety of proliferating eukaryotic cells (Vincent et al., 1996). We also reported that the conserved M-phase MPM-2 phosphoepitope is abundant in NFT-containing neurons in AD, but is not detected in neurons of normal brain (Vincent et al., 1996). Based on these findings, we hypothesized that a mitotic posttranslational mechanism participates in the formation of NFT and the death of neurons in AD.

To gather support for this hypothesis, we first isolated mitotic kinase from brain using the yeast $\mathrm{p} 13 \mathrm{suc} 1$ protein as affinity ligand and compared the phosphorylation activity of the kinase from AD brain with that of normal brain. We found that mitotic kinase activity is elevated in $\mathrm{AD}$ brain in comparison with normal. We

Received Dec. 19, 1996; revised March 4, 1997; accepted March 5, 1997.

This work was supported by National Institute of Mental Health Grants 38623 and AG06803. We thank J. Wang for purified cdk5; M. Goedert for clone Tau40; A. Rajan for BW1100 mouse lymphoma cells; Michael Cammer of the AECOM Ultrastructural Analysis Facility for his technical advice; P. Davies for his helpful discussions of the experiments and the manuscript; C. Weaver for assisting with the analysis of mouse brain sections; and B. Norton, F.-C. Chiu, and T. R. Kollmann for reviewing the manuscript and for their valuable advice and criticism.

Correspondence should be addressed to Dr. Inez Vincent, Department of Pathology, F518, Albert Einstein College of Medicine, 1300 Morris Park Avenue, Bronx, NY, 10461.

Copyright (C) 1997 Society for Neuroscience $0270-6474 / 97 / 173588-11 \$ 05.00 / 0$ also have found that the increase in mitotic kinase activity in AD occurs as a result of specific reexpression and activation of the cdc2 kinase and its cyclin partner cyclin B1 in neurons undergoing AD pathology. The M-phase proteins are localized to those AD neurons containing accumulations of mitotic phospho-epitopes and are isolated as a functional complex with PHF protein. In vitro studies show that of several proline-directed protein kinases, only the cdc2/cyclin B complex produces the mitotic TG/MC phosphoepitopes in recombinant tau protein. Taken together, these data provide strong support for our hypothesis that a mitotic posttranslational process may operate in dying neurons in $\mathrm{AD}$.

\section{MATERIALS AND METHODS}

Antibodies. The TG/MC monoclonal antibodies recognize phosphorylated epitopes in paired helical filaments (PHF) and conserved mitotic phospho-epitopes in dividing eukaryotic cells (Vincent et al., 1996). PHF-1 reacts with a phospho-epitope in PHF and was raised against gel-purified PHF protein (Greenberg and Davies, 1990). MPM-2, human $\mathrm{C}-\mathrm{T}$ cdc2 polyclonal, human PSTAIRE monoclonal, and human cyclin B1 monoclonal antibodies were obtained from UBI (Lake Placid, NY). The active/inactive cdc2 antibodies were obtained from New England Biolabs (Beverly, MA).

Immunocytochemistry. Human autopsy brain tissue and rapidly removed brains from C57 black mice were immersion-fixed in $4 \%$ paraformaldehyde for $16 \mathrm{hr}$. Vibratome sections $(40 \mu \mathrm{m})$ were cut and immunostained as described in Vincent et al. (1996), except that detection of bound primary antibody was with alkaline phosphatase conjugated, isotype-specific secondary antibody (Southern Biotechnology Associates, Alabaster, AL) and BCIP chromogen (Pierce, Rockland, IL). MPM-2 was used at 1:500; the C-T cdc2, PSTAIRE, and cyclin B1 antibodies were used at $4 \mu \mathrm{g} / \mathrm{ml}$; and the active/inactive antibodies were used at 1:200. Clinicopathological data for the cases used in this study are presented in Table 1.

Statistical analysis. Mann-Whitney Rank Sum Tests and Pearson product-moment correlations were performed using SigmaStat for Windows (Jandel Scientific Software, San Rafael, CA). A $p<0.05$ was considered statistically significant. 


\begin{tabular}{|c|c|c|c|c|c|c|c|c|c|c|}
\hline Case & Age & PMI & Sex & TG-3 & MPM-2 & C-T cdc2 & PSTAIRE & Active & Inactive & сус B1 \\
\hline \multicolumn{11}{|c|}{ Normal } \\
\hline 9452 & 44 & 3 & $\mathrm{~F}$ & - & - & - & - & - & - & + \\
\hline 9593 & 51 & 20 & M & - & - & - & - & - & - & - \\
\hline 9531 & 55 & 13 & M & - & - & - & - & - & - & + \\
\hline 9532 & 55 & 2 & M & - & - & - & - & - & - & + \\
\hline 9545 & 69 & 16.5 & M & - & - & - & - & - & - & - \\
\hline 9568 & 75 & 8.5 & $\mathrm{~F}$ & $-*$ & $-*$ & $-*$ & - & $-*$ & - & - \\
\hline 9578 & 90 & 3.5 & M & - & - & - & - & - & - & + \\
\hline \multicolumn{11}{|l|}{$\mathrm{AD}$} \\
\hline 9308 & 55 & 11 & $\mathrm{~F}$ & + & + & + & - & + & - & - \\
\hline 9575 & 60 & 3.5 & $\mathrm{~F}$ & + & + & + & + & + & - & + \\
\hline 9566 & 73 & 3 & M & + & + & + & $-/+$ & + & - & + \\
\hline 9548 & 74 & NA & $\mathrm{F}$ & + & + & - & + & + & - & + \\
\hline 9533 & 80 & 3 & M & + & + & + & + & + & - & + \\
\hline 9586 & 86 & 5 & $\mathrm{~F}$ & + & + & + & - & + & - & - \\
\hline 4581 & 89 & 19 & $\mathrm{~F}$ & + & + & $-/+$ & - & + & - & - \\
\hline 9537 & 89 & 3 & M & + & + & + & + & + & - & + \\
\hline 9258 & 95 & 12 & $\mathrm{~F}$ & + & + & + & - & + & - & - \\
\hline
\end{tabular}

+, Neurons positive; -, neurons negative; *, a few NFT-containing neurons in the CA1-CA2 region positive; NA, not available; PMI, postmortem interval.

Immunofluorescent staining and confocal microscopy. Double immunofluorescent staining was conducted as described previously (Vincent et al., 1996) but using 5\% bovine albumin in TBS to block nonspecific binding of antibody and for dilution of primary and secondary reagents. Detection of bound primary antibody was with biotin-conjugated isotypespecific secondary antibodies (Southern Biotechnology Associates) at a 1:500 dilution, followed by incubation with strepavidin coupled to $\mathrm{Cy} 2$, Cy3, or Cy5 fluorophores (Biological Detection Systems, Pittsburgh, PA) at a 1:500 dilution. The concentrations of primary antibodies used were the same as with the immunocytochemical studies above. Confocal scanning laser microscopy was conducted using a BioRad MRC 600 fitted with Nikon Diaphot optics.

P13suc1 precipitation. Dissected pieces of human brain stored at $-70^{\circ} \mathrm{C}$ were thawed and homogenized in $10 \mathrm{vol}$ of TBS containing $0.5 \%$ Triton X-100, 0.2\% SDS, 2 mM PMSF, 2 mm EGTA, $25 \mu \mathrm{M}$ leupeptin, $10 \mathrm{~mm}$ $\mathrm{NaF}, 1 \mathrm{~mm} \beta$-glycerophosphate, and $1 \mathrm{~mm} \mathrm{Na}$ vanadate. The homogenates were centrifuged in an Eppendorf centrifuge for $15 \mathrm{~min}$ to yield a detergent-solubilized extract. P13suc1-agarose beads (UBI) were used to isolate mitotic kinase complex from brain extracts. In some experiments, a GST-p13suc1 fusion protein product coupled to agarose was used and yielded identical results. Therefore, the two reagents were used interchangeably. Two microliters of a $50 \%$ bead slurry were incubated per 200 $\mu \mathrm{g}$ of protein for $1.5 \mathrm{hr}$ at $4^{\circ} \mathrm{C}$. The precipitates were collected by centrifugation and washed twice with lysis buffer. For assays of mitotic kinase activity, $\mathrm{p} 13 \mathrm{suc} 1$ precipitates were washed twice with $20 \mathrm{vol}$ TBS to reduce the detergent concentration and were reconstituted to $20 \mu \mathrm{l}$ with TBS containing $6 \mu \mathrm{g}$ of histone H1 (Boehringer Mannheim, Indianapolis, IN), $1 \mathrm{~mm}$ DTT, $2 \mathrm{~mm}$ EGTA, $5 \mu \mathrm{g} / \mathrm{ml}$ Walsh inhibitor (Sigma, St. Louis, MO), $50 \mu \mathrm{g} / \mathrm{ml}$ PKC inhibitor peptide (Santa Cruz Biotechnologies, Santa Cruz, CA), $50 \mu \mathrm{M}$ KN-62 CAM kinase inhibitor (Seikagaku, Rockville, MD), $10 \mathrm{mM} \mathrm{MgCl}$, and $20 \mu \mathrm{M}$ ATP. The reaction was initiated by the addition of $\gamma_{-}{ }^{32} \mathrm{P}$-labeled ATP, allowed to proceed for $30 \mathrm{~min}$ at RT, and stopped with sample buffer and boiling. After SDS-PAGE, gels were stained with Coomassie Blue, dried, and subjected to autoradiography or quantitative analysis by Phosphoimager. Phosphorylation activity was calculated as a percentage relative to the sample with the highest extent of phosphorylation in each experiment. For immunoblot analysis of p13suc1 precipitates, $15 \mu \mathrm{l}$ of the bead slurry was used for precipitation from $0.5 \mathrm{mg}$ of protein of brain extract. The entire precipitate was loaded in one lane. For immunoblotting of brain extracts, $125 \mu \mathrm{g}$ of protein was loaded per lane.

Phosphorylation of recombinant tau protein by cdc2/cyclin B. Clone hTau40 containing the entire coding sequence of the longest adult isoform of tau was obtained from M. Goedert. After excision with NdeI and EcoRI and blunting with the Klenow fragment of Escherichia coli DNA polymerase, the tau sequence was ligated into the SmaI cut pQE bacterial expression system (Qiagen, Hilden, Germany). This construct contained an N-terminal polyhistidine tag that allowed for affinity purification on a $\mathrm{Ni}^{2+}$-conjugated agarose column. Purified $\mathrm{cdc} 2 /$ cyclin B kinase, MAP kinase, and GSK-3 $\beta$ kinase were obtained in active form from Upstate Biotechnology. Catalytically active cdk5 was a generous gift from J. Wang (University of Calgary, Alberta, Canada). Kinase activities were standardized at $40 \mathrm{U}$, and $0.5 \mu \mathrm{Ci} \gamma^{32} \mathrm{P}$-labeled ATP $/ \mathrm{mg}$ substrate protein was added to each reaction to verify phosphate incorporation by autoradiography. Additional standardization of kinase activity was performed using $6 \mu \mathrm{g}$ of histone $\mathrm{H} 1$.

\section{RESULTS}

\section{Mitotic kinase activity is elevated in AD brain}

Mitotic kinase activity from AD brain was compared with that from normal brain. Several studies have demonstrated that mitotic kinase can be purified from mammalian cells as a stable, functionally active complex, using the fission yeast cdc 2 regulatory protein p13suc1 as an affinity ligand (Brizuela et al., 1987; Samiei et al., 1991; Tournier et al., 1991; Azzi et al., 1994). P13suc1conjugated agarose beads were used for isolation of mitotic kinase from brain, and the resulting precipitates were assayed for phosphorylating activity against the exogenous substrate histone H1. The hippocampus and temporal cortex, two brain regions affected early in AD progression (Braak and Braak, 1991), were examined. $\mathrm{H} 1$ phosphorylation activity in $\mathrm{p} 13 \mathrm{suc} 1$ precipitates from both regions of AD brain was significantly higher than in similar samples from normal brain (Fig. $1, p<0.001$ for hippocampus, and $p<0.002$ for temporal cortex). The normal hippocampus had $26.3 \pm 16.16 \%$ (mean $\pm \mathrm{SD})$ the phosphorylation activity of $\mathrm{AD}$ ( $n=14 \mathrm{AD}, 14$ normal), and normal temporal cortex showed $35.7 \pm 26.6 \%$ of the activity of $\mathrm{AD}(n=12 \mathrm{AD}, 12$ normal). Although the mean age in the AD group (75.2 \pm 10.5$)$ was higher than that of the normal subjects $(56.5 \pm 22.6)$, there was no apparent trend within each group for mitotic kinase activity to increase with increasing age. Other factors such as gender or the postmortem interval between death and autopsy (normal subjects, $11.8 \pm 5.1 \mathrm{hr}$; AD subjects, $11.5 \pm 6.6 \mathrm{hr}$ ) did not appear to account for the difference in mitotic kinase activity between AD and normal cases. 

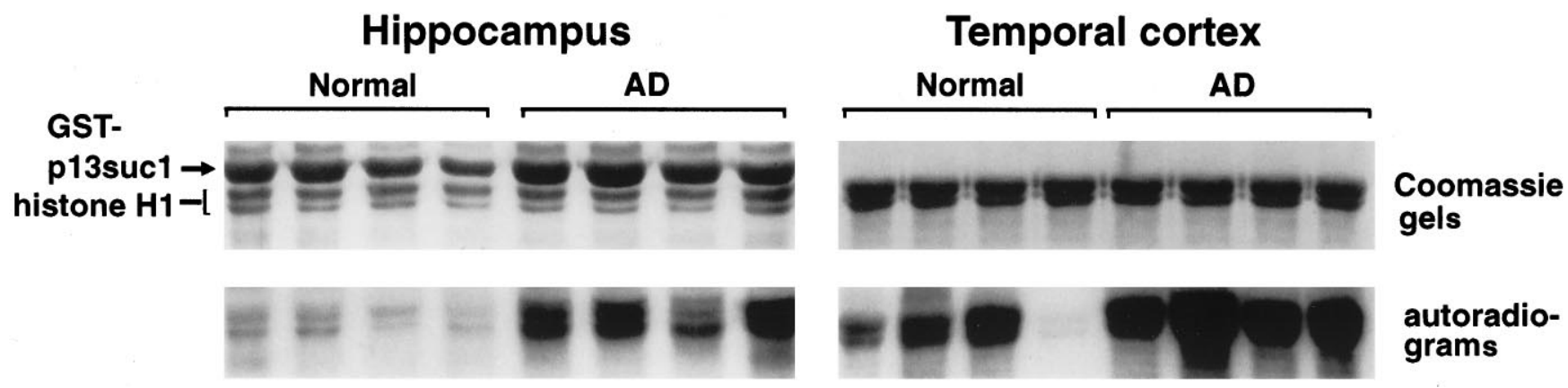

Figure 1. Mitotic kinase activity is higher in AD than in normal brain. Normal and AD extracts were subjected to precipitation with p13suc1-agarose and the precipitates assayed for histone H-1 phosphorylation activity. Representative data from two sets of four normal and four AD cases are shown. Top panels show the histone H1 bands and, with the hippocampus, the position of the GST-p13suc1 fusion product as revealed by Coomassie blue staining. P13suc1-agarose and GST-p13suc1-agarose gave identical results and were used interchangeably. Bottom panels show the corresponding autoradiograms. Phosphorylation of $\mathrm{H} 1$ measured by Phosphoimager is higher in AD than in normal brain.

\section{Cdc2 is present in NFT-bearing neurons in AD}

For mitotic kinase to participate in NFT formation, it must be found in neurons in AD. Therefore, we examined the presence of the cdc2 kinase in AD brain. Tissue sections from the hippocampus were immunostained with a variety of cdc2-specific antibodies. An antibody (designated $\mathrm{C}-\mathrm{T}$ cdc2) recognizing the unique $\mathrm{C}$-terminal sequence (DNQIKKM) in human cdc2 showed robust staining of neurons containing NFT (Fig. 2). A few neuritic processes associated with senile plaques were also stained, whereas staining of dystrophic neurites in the neuropil was scarce in comparison with TG-3. A monoclonal antibody against human cdc2 sequence containing the PSTAIRE motif, characteristic of the three M-phase kinases cdc2, cdk2, and cdk3 (Meyerson et al., 1992), also stained NFT-containing neurons, but not normal neurons (Fig. 2). The majority of NFT stained with the two cdc2 antibodies appeared intracellular, and staining of extracellular or "ghost tangles" was rare. When the C-T cdc2 antibody was absorbed with its peptide immunogen, subsequent staining of neurons was eliminated, confirming specificity of the immunocytochemistry (data not shown). As with normal human brain, mouse brain that was fixed under similar conditions exhibited no neuronal staining with the cdc2 antibodies (Fig. 2), although cells that have been shown to retain proliferative capacity in adult brain, for example in the subependymal zone, choroid plexus, olfactory bulb, and endothelial lining of capillaries, were stained (data not shown). Variable numbers of capillary endothelial and glial cells were stained for cdc2 in both $\mathrm{AD}$ and normal human brain. In some cases, a few astrocytes were labeled in gray and white matter, but there was no significant increase in staining of glial cells in $\mathrm{AD}$ compared with normal subjects, even though gliosis is common in AD. Overall, there was a significant positive correlation between cdc2 and PSTAIRE immunoreactivities with TG-3 immunoreactivity in AD and with MPM-2 immunoreactivity.

\section{Catalytically active cdc2 is present in NFT-bearing neurons in AD}

A critical regulatory step in M-phase activation of cdc2 is the dephosphorylation of tyr-15 by the cdc25 phosphatase (Galaktionov et al., 1995; Hunter, 1995; Watanabe et al., 1995). A pair of antibodies distinguishing the "active" (tyr-dephosphorylated) and "inactive" (tyr-phosphorylated) forms of human cdc2 was used to determine whether neuronal cdc2 is catalytically active. The specificity of these antibodies was confirmed by immunoblot analysis (see below). Numerous NFT-containing neurons were immunolabeled with the active kinase antibody in $\mathrm{AD}$ brain. As with the
C-T cdc2 and PSTAIRE antibodies, the NFT recognized by the active kinase antibody were chiefly intracellular. Neuritic elements associated with senile plaques were also prominently stained (Fig. 3, bottom row, NP). In contrast to this robust staining of neurofibrillary lesions with the active kinase antibody, the antibody recognizing inactive cdc2 did not stain a single NFT or neuron in AD brain, but reacted only with blood vessels and occasional glial cells (Fig. 3). In normal brain, no active kinasepositive neurons were obvious, but blood vessels and glia were detected with both antibodies (Fig. 3). In some advanced cases of $\mathrm{AD}$, glial cells were discerned faintly with the active kinase antibody, but with an intensity considerably less than that of the NFT staining (Fig. 3, bottom row, active). Not a trace of neuronal staining was seen in these cases with the inactive kinase antibody, although a similar pattern of faintly stained glia was apparent. These data suggest that active cdc2 is predominantly found in NFT-bearing neurons in AD brain but is absent in normal brain neurons. In $\mathrm{AD}$, active kinase immunoreactivity was significantly correlated with cdc2, PSTAIRE, TG-3, and MPM-2 immunoreactivities. As with normal human brain, neither active nor inactive kinase antibody displayed any neuronal staining in adult mouse brain, although the antibodies stained proliferating cells in the subependymal layer, choroid plexus, and blood vessels (data not shown).

\section{Cyclin B1 is present in NFT-bearing neurons of AD brain}

Because optimal cdc2 activation requires interaction with cyclin B, a $62 \mathrm{kDa}$ regulatory co-factor (Draetta and Beach, 1988; Solomon et al., 1990), immunocytochemical analyses were conducted to examine the occurrence of the cyclin in $\mathrm{AD}$ neurons. A monoclonal antibody against human cyclin B1 showed widespread staining of hippocampal pyramidal neurons in $\mathrm{AD}$ brain. In some $\mathrm{AD}$ cases (Fig. 4, $A D 1$ ), cyclin B1 occupied the entire neuronal cell body including the nucleus, whereas in other AD cases, cyclin B1 was principally nuclear, with some interspersed cytoplasmically stained neurons $(A D 2)$. A significant correlation was observed between cyclin B1 staining and cdc2 and active cdc2. Three of seven normal cases also had detectable levels of cyclin B1 in neuronal nuclei, whereas the remainder were totally negative (Fig. 4). Although statistical analysis showed that cyclin B1 staining was inversely correlated with postmortem delay, a lack of staining was noted in normal cases with short postmortem delay. As with cdc2, few cyclin B1-positive neurites were observed in AD (data not shown), and blood vessel staining was seen in most $\mathrm{AD}$ and 


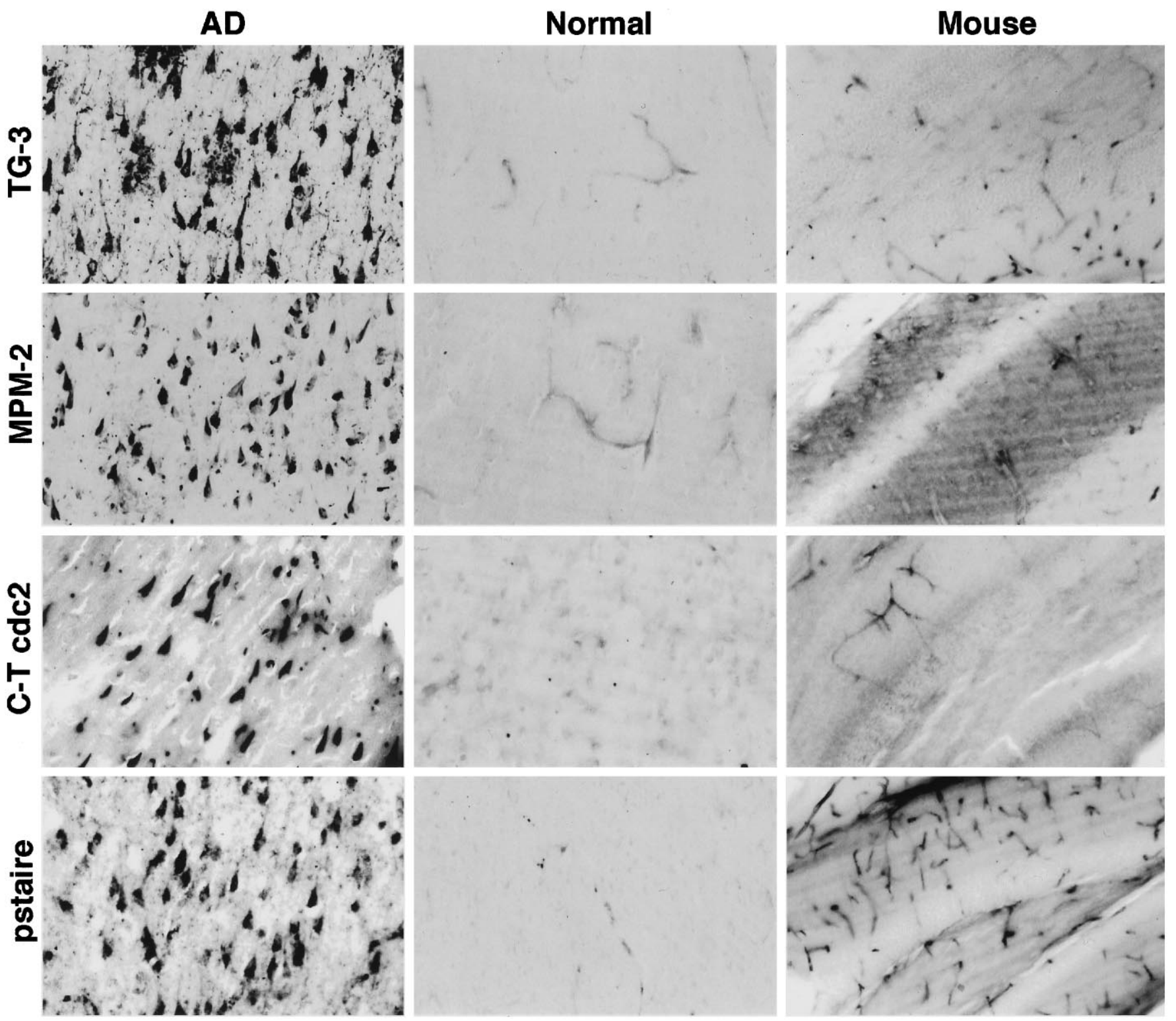

Figure 2. The cdc2 kinase is present in NFT-containing neurons in AD. Hippocampal tissue sections from AD (left panel), normal human (middle panel), and mouse brain (right panel) were stained with the indicated antibodies. Light micrographs of representative cases are shown. The TG-3 and MPM-2 rows demonstrate the specific occurrence of mitotic phospho-epitopes in AD neurons with NFT, with no similar staining in normal brain. NFT-bearing neurons are also stained with C-T cdc2 and PSTAIRE antibodies. In normal human and mouse brain, no neuronal staining is obvious with the cdc2 antibodies, but blood vessel endothelial cells are stained. Magnifications for the human and mouse illustrations are $150 \times$ and $75 \times$, respectively.

normal cases. In mouse brain, cyclin B1 was not detected in neurons, but appeared abundant in the choroid plexus, subependymal lining of the lateral ventricles, and endothelial cells of blood vessels (data not shown).

\section{Cdc2 and cyclin B1 co-exist in AD neurons and co- localize with MPM-2 and TG-3 phospho-epitopes}

To form an "active" mitotic kinase complex, it is essential that cdc2 and cyclin B1 be present within the same neurons. We examined this possibility in double-labeling experiments. In AD cases in which the entire neuronal cell body contained cyclin B1 (for example, AD1 in Fig. 4), confocal microscopic analysis revealed co-localization of cyclin immunofluorescence (red) Fig. $5 b, c)$ with cdc 2 immunofluorescence (green) $(a, c)$. In other AD cases with predominantly nuclear cyclin B1 (for example, AD2 in
Fig. 4), several neurons with cyclin B1-positive nuclei (violet) displayed cytoplasmic, NFT-associated, cdc2 immunoreactivity (brown) (Fig. 5d, large arrows). However, some cyclin B1-positive neurons had little detectable cdc2 ( $d$, small arrow).

To demonstrate activation of cdc2 in NFT-bearing neurons, the relationship between $\mathrm{C}-\mathrm{T}$ cdc2 immunofluorescence and the active kinase antibody was examined. Virtually all C-T cdc2-labeled NFT and neuritic plaques (red) (Fig. 5f,g) were stained for active kinase (green, $e, g$ ), with co-localization of the two. The coexistence of cdc2 and cyclin B1 in neurons would only be of relevance to $\mathrm{AD}$ pathology if the kinase complex co-localized with AD-specific phospho-epitopes. The relative distributions of the kinase and the mitotic phospho-epitopes recognized by MPM-2 and TG-3 were therefore compared. There was remarkable over- 

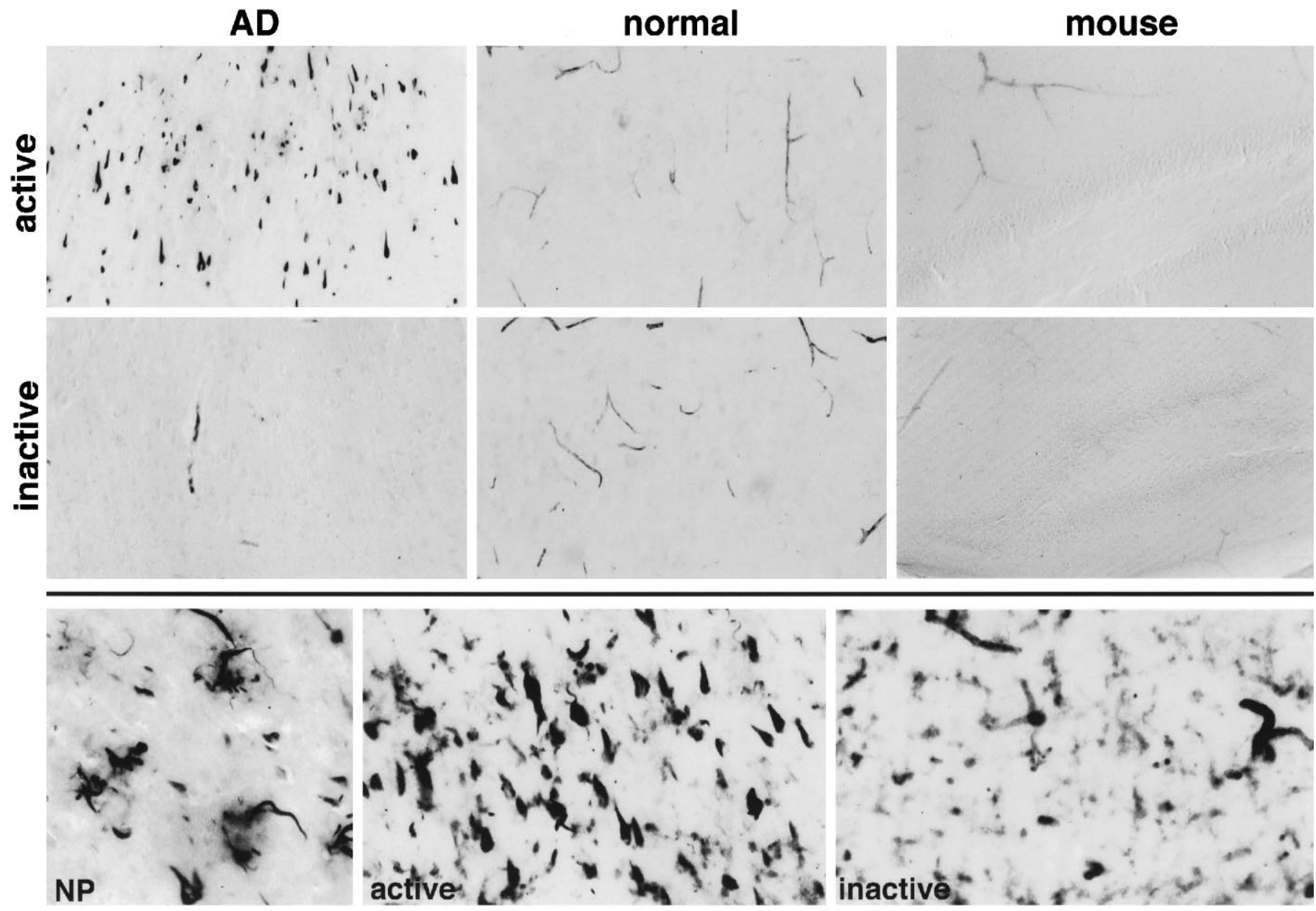

Figure 3. Catalytically active cdc2 is present in NFT-containing neurons in AD. Hippocampal tissue sections from AD (left panel), normal human (middle panel), and mouse brain (right panel) were stained as indicated (active kinase, top and bottom rows; inactive kinase, middle row), and light micrographs of representative cases are shown. The active kinase antibody stains AD neurons with NFT and some blood vessels in normal brain. Neurites in neuritic plaques $(N P$, bottom row $)$ are also positive with the active kinase antibody. Some AD cases (bottom row) showed weaker staining of glial cells with the active kinase antibody in addition to the marked reactivity with NFT. None of the NFT in these cases stained positive with the inactive kinase antibody (bottom row, inactive), although blood vessels and glia were stained. Magnifications for the top and middle rows are $75 \times$; for the NP, 400 $\times$; and for the remaining panels in the bottom row, $200 \times$.

Figure 4. Cyclin $\mathrm{B} 1$ is present in neurons of $\mathrm{AD}$ brain. Hippocampal tissue sections from AD (top row), normal human (bottom row, left), and mouse brains (bottom row, right) were stained with human cyclin $\mathrm{B} 1$ monoclonal antibody. In some $\mathrm{AD}$ cases $(A D 1)$, staining of the neuronal cytoplasm and nucleus was observed, but in other cases, $(A D 2)$, primarily the neuronal nucleus (small arrows) and, occasionally, neurons (large arrow) were stained. Positive neuronal nuclei were also observed in some normal cases (shown), but not in mouse. Magnifications for the human and mouse illustrations are $150 \times$ and $75 \times$, respectively.
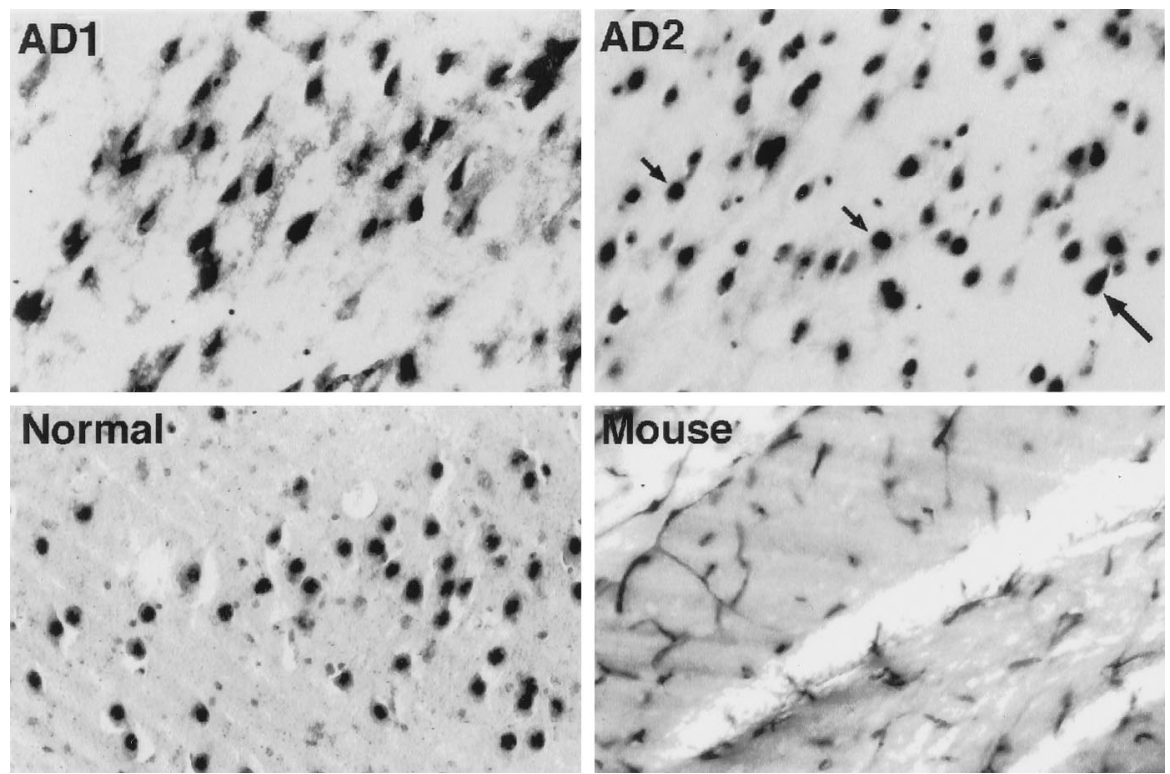

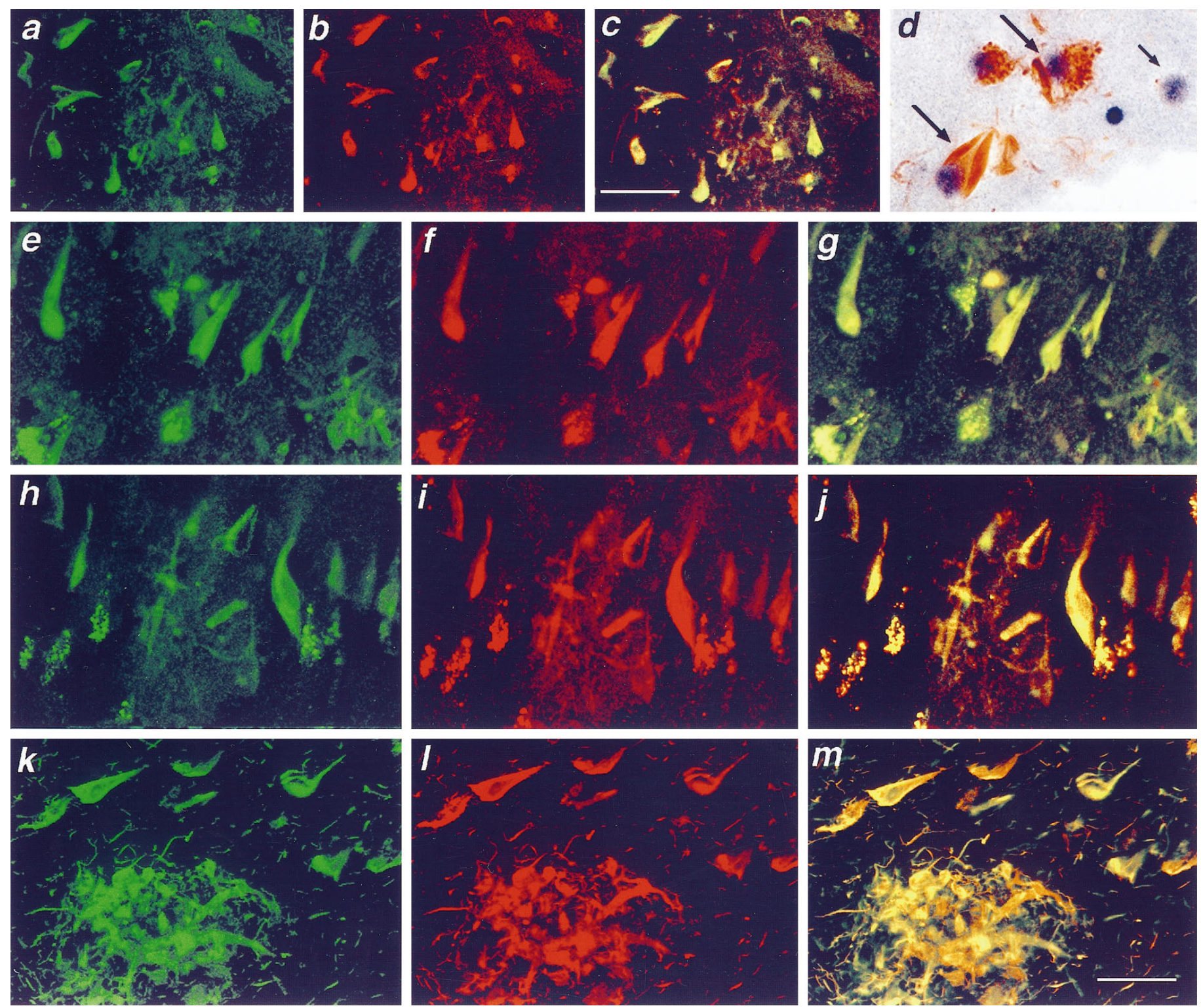

Figure 5. Cdc2, cyclin B1, and TG-3/MPM-2 phospho-epitopes co-localize in AD neurons. Confocal micrographs illustrate AD hippocampus double-stained as follows: active kinase $(a)$, cyclin B1 $(b)$, and the merged image $(c)$ showing co-localization of cyclin B1 with active kinase in neurons containing NFT; active kinase $(e)$, C-T cdc2 $(f)$, and the merged image $(g)$ showing co-localization of C-T cdc2 with active kinase immunofluorescence; active kinase $(h)$, MPM-2 $(i)$, and the merged image $(j)$ showing co-localization of active kinase and MPM-2 phospho-epitope; and active kinase $(k)$, TG-3 $(l)$, and the merged image $(m)$ showing co-localization of active kinase and TG-3 phospho-epitope. $d$ is a light micrograph showing double staining of AD hippocampus with primarily nuclear cyclin B1 staining (violet) and cytoplasmic active kinase (brown). Both proteins were found in the same neurons (large arrows), but some cyclin-positive neurons lacked active kinase immunoreactivity (small arrow). Scale bars: $a-c, 12 \mu \mathrm{m} ; e-m, 17.6 \mu \mathrm{m}$. Magnification in $d, 500 \times$.

lap in the location of both C-T cdc2 and active kinase (Fig. 5, green, $h, j, l, m)$ with MPM-2 (red $, i, j)$ and TG-3 immunofluorescence $(r e d, k, m)$. As was expected, however, the majority of TG-3-positive neurites and most late NFT were not stained for cdc2 (data not shown).

\section{Cdc2 antibodies that stain AD neurons do not cross- react with cdk5}

Although cdc2 and other M-phase kinases are absent in mature neurons of adult brain (Hayes et al., 1991; Meyerson et al., 1992; Okano et al., 1993), a related kinase, cdk5, is expressed abundantly in these cells (Tsai et al., 1993; Lew and Wang, 1995). To verify that the cdc2 antibodies used in the above immunocytochemical studies reacted with cdc 2 and not $\operatorname{cdk} 5$, the specificity of the antibodies was tested by immunoblot analysis. Immunoreactivity with purified cdk5 was examined in relation to reactivity with cdc2 from exponentially growing or mitotic human neuroblastoma cells. A monoclonal antibody specific for cdk5 showed comparable cdk5 immunoreactivity in all the samples. Although the C-T cdc2 and PSTAIRE antibodies reacted strongly with the $34 \mathrm{kDa} c d c 2$ kinase, neither displayed any reactivity with purified cdk5 (Fig. 6). These results agree with the absence of the C-T cdc2 sequence and the substitution of the PSTAIRE motif by PSSALRE in cdk5. The active kinase antibody reacted predominantly with catalytically active cdc2 in the mitotic lysate but sparingly with the electrophoretically retarded, inactive kinase in control (Fig. 6), and reciprocal results were seen with the inactive kinase antibody. 

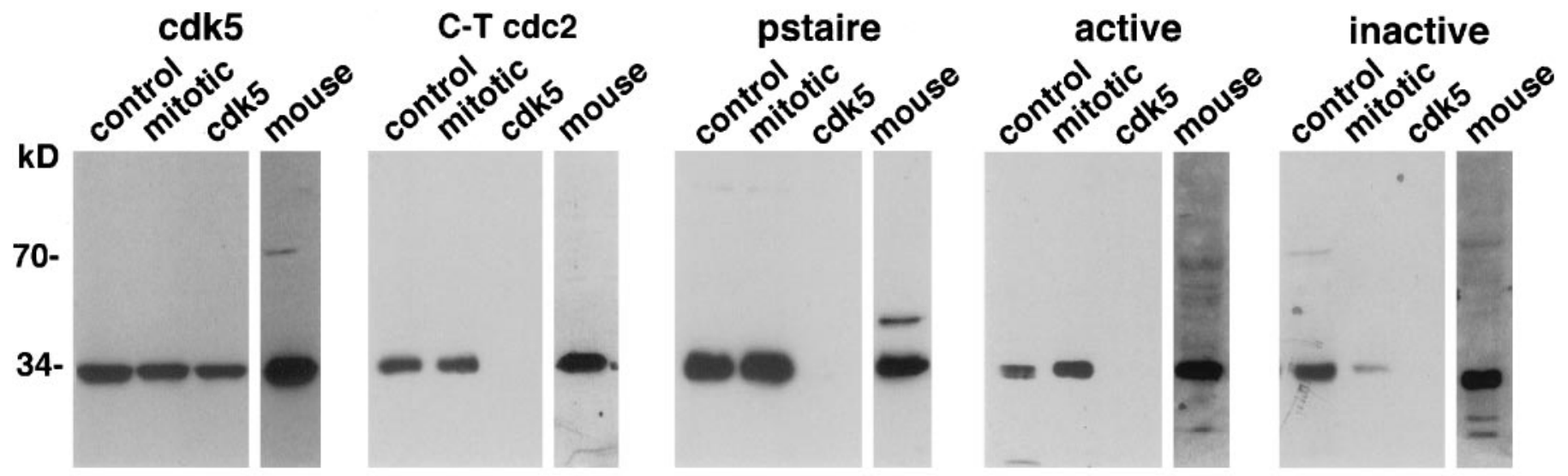

Figure 6. $\mathrm{Cdc} 2$ antibodies that stain $\mathrm{AD}$ neurons do not cross-react with cdk5. Immunoblot analysis was performed with the indicated antibodies and purified cdk5 (lane cdk5) or lysates from exponentially growing (control) and mitotic neuroblastoma cells and mouse lymphoma cells. Detection was by ECL with exposures of $20 \mathrm{sec}$ to $3 \mathrm{~min}$. The C-T cdc2, pstaire, active, and inactive kinase antibodies appropriately identified the $34 \mathrm{kDa}$ cdc2 kinase in the human and mouse cell lysates. None of the cdc2 antibodies react with cdk5.
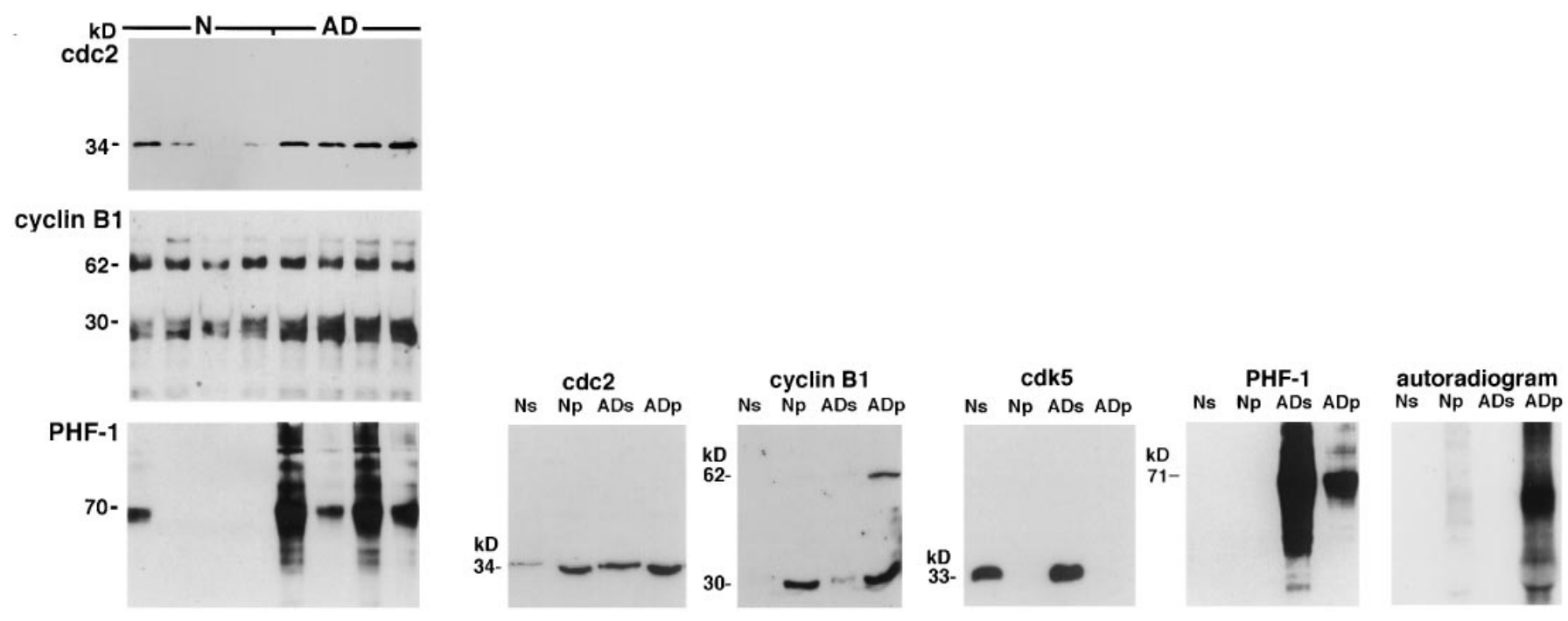

Figure 7. A, PHF-tau co-precipitates with Cdc2 and cyclin B1 in p13suc1 precipitates from brain. P13suc1 precipitates from four normal and four AD cases were analyzed by immunoblotting. The data are representative of 12 normal and 12 AD cases. Cdc2 was detected with CT-cdc2, PSTAIRE, and another cdc2-specific monoclonal antibody (shown). The amounts of cdc2 and cyclin B1 recovered in the p13suc1 precipitates from AD were higher than those from normal brain. Replicate blots were stained with the PHF-1 antibody to show the co-precipitation of PHF-tau in the AD p13suc1 precipitates. Similar staining of PHF-tau in the AD p13suc1 precipitates was seen with Alz-50, TG-3, and MC15 (data not shown). Only 1 of 12 normal cases showed PHF-1 immunoreactivity in the p13suc1 precipitate. This one case had hippocampal NFT when examined histopathologically. $B$, PHF-tau is phosphorylated by the active mitotic kinase complex in p13suc1 precipitates. P13suc1 precipitates from normal $(N p)$ and $\mathrm{AD}(A D p)$ were analyzed by immunoblotting in relation to the starting extracts from which they were derived ( $N s$ and $A D s$, respectively). Cdc2 and cyclin B1 are recovered in the p13suc1 precipitates in larger amounts in $\mathrm{ADp}$ relative to $\mathrm{Np}$. The $62 \mathrm{kDa}$ cyclin $\mathrm{B} 1$ is prominent in $\mathrm{ADp}$ but was evident in the other lanes as well, after longer ECL exposures. The $30 \mathrm{kDa}$ cyclin B1-positive protein may be a degradation product of the $62 \mathrm{kDa}$ cyclin. The nonmitotic cdk5 kinase is not recovered in the p13suc1 precipitates. A fraction of the total PHF-1-immunoreactive NFT protein in the AD extract (ADs) co-precipitates with the mitotic kinase complex $(A D p)$. Incubation of the p13suc1 precipitates with $\gamma^{-32} \mathrm{P}$-labeled ATP resulted in marked incorporation of labeled phosphate into NFT protein in the ADp.

Neither active nor inactive kinase antibodies reacted with cdk5. Thus, three cdc2 antibodies (C-T cdc2, PSTAIRE, and active), each recognizing independent primary sequence epitopes in cdc2 and having no cross-reactivity with cdk5, specifically label diseased neurons in AD brain. All the human cdc2 antibodies react with mouse cdc2 on blots, verifying that the negative staining for cdc2 in mouse neurons (Figs. 2, 3) is attributable to the absence of kinase in these cells and not to an inability of the antibodies to recognize the mouse protein.

\section{PHF protein is complexed with active mitotic kinase and phosphorylated by the kinase in vitro}

As an assurance that the elevated p13suc1-precipitated kinase activity in $\mathrm{AD}$ (Fig. 1) was mitotic, we analyzed precipitates from $8 \mathrm{AD}$ and 8 normal cases by immunoblotting. Cdc 2 and cyclin B1 were clearly evident in the precipitates, and the recovery of these proteins in the $\mathrm{AD}$ precipitates was higher than that in the normal precipitates (Fig. 7A,B). A cyclin-B1-immunoreactive $30 \mathrm{kDa}$ band was prominent in the p13suc1 precipitates and probably 
represents a degradation product of the $62 \mathrm{kDa}$ cyclin, because a similar band was visible in brain extracts and in lysates from human neuroblastoma and mouse lymphoma cell lines (data not shown). Importantly, no cdk5 was detected in the p13suc1 precipitates, although ample amounts of the kinase were present in the brain extracts (Fig. 7B). This finding agrees with previous reports of the inability of p13suc1 to interact with nonmitotic cyclindependent kinases (Meyerson et al., 1992; Azzi et al., 1994).

If mitotic kinases have any role in phosphorylation of NFT components, it seemed likely that these substrates would be associated physically with the kinase. The cytoskeletal protein tau is a principal component of PHF in NFT (Goedert et al., 1992). Using an established PHF-tau antibody, PHF-1 (Greenberg and Davies, 1990), we detected a typical AD-specific pattern of PHFderived protein in 13 suc1 precipitates from $\mathrm{AD}$ (Fig. $7 A$ ). One normal case displayed PHF-1 immunoreactivity in the p13suc1 precipitate. This case was found to contain hippocampal, but no neocortical, NFT at neuropathological evaluation. The remaining normal subjects had no detectable PHF-1 immunoreactivity in the p13suc1 mitotic kinase fraction, which was consistent with the lack of PHF-1 staining in immunocytochemical studies of these cases. A similar AD-specific pattern of staining was observed in $\mathrm{AD}$ p13suc1 precipitates with the Alz-50, MC15, and TG-3 antibodies (data not shown). Only a fraction of the total PHF-1 reactivity from the $\mathrm{AD}$ extracts was recovered in the $\mathrm{p} 13 \mathrm{suc} 1$ precipitates (Fig. $7 B$ ), reflecting a transient interaction between mitotic kinase and PHF substrate or the precipitation with p13suc1 of both neuronal and non-neuronal cdc2. PHF-1-immunoreactive protein bound to mitotic kinase in the presence of $0.5 \%$ Triton $\mathrm{X}-100$ / $0.2 \%$ SDS, suggesting a stringent association, and in the absence of detergents, suggesting that binding was not induced by the experimental conditions. When the entire p13suc1-precipitated mitotic kinase complex was incubated with $\gamma_{-}{ }^{32} \mathrm{P}$-labeled ATP, phosphorylation of the co-precipitated PHF-1-immunoreactive protein was observed in the AD samples (Fig. $7 B$ ). The phosphorylation of the PHF-1-immunoreactive protein was so intense, it was difficult to discern any additional phosphorylated substrates in the mitotic kinase complex.

\section{Preferential creation of the TG/MC phospho-epitopes in recombinant tau by cdc2/cyclin B kinase}

Given that PHF-tau is the principal antigen recognized by the TG/MC antibodies in NFT (Vincent et al., 1996), and that active cdc2/cyclin B1 co-localizes with PHF-tau in AD and phosphorylates the proteins in vitro, we tested the possibility that cdc $2 /$ cyclin $\mathrm{B}$ produces the TG/MC phospho-epitopes in PHF-tau. Because none of these antibodies react with normal tau protein (Vincent et al., 1996), we looked for the generation of TG/MC immunoreactivity after incubation of recombinant tau with purified cdc $2 /$ cyclin B kinase. On account of their striking similarity in phosphorylation site specificity (Hall and Vulliet, 1991; Nigg, 1993), other proline-directed protein kinases, which have been shown to phosphorylate tau [i.e., MAP kinase (Drewes et al., 1992), GSK-3 $\beta$ kinase (Mandelkow et al., 1992), and cdk5 (Paudel et al., 1993)], were also examined. Using equivalent units of the active kinases standardized by reaction against histone $\mathrm{H} 1$ as substrate, incorporation of labeled phosphate into tau was observed with all the kinases (Fig. 8A). Under these conditions, every one of the kinases produced the PHF-1 phospho-epitope, which contains a proline-directed serine residue at position 396 of tau (Otvos et al., 1994), but is not M-phase-specific (Vincent et al., 1996). In contrast, only cdc2, but not MAP kinase, GSK-3, or the neuronally
A) 32P incorporation
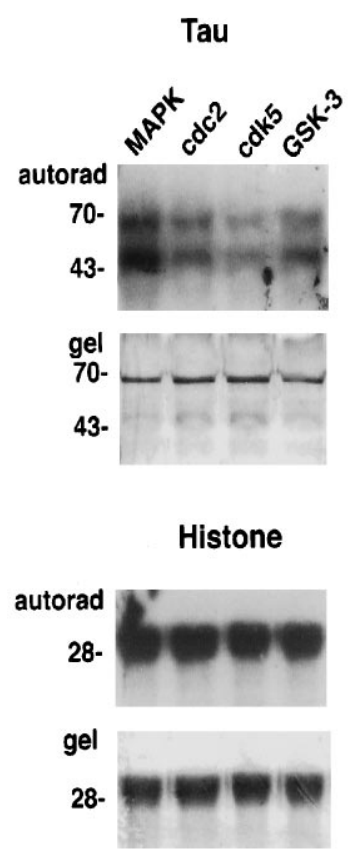

B) Tau immunoreactivity

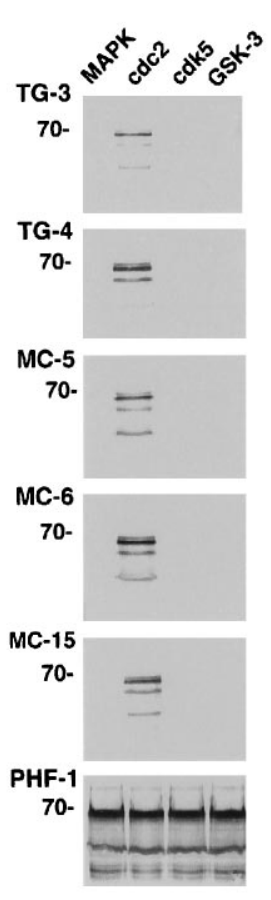

Figure 8. Preferential creation of the TG/MC phospho-epitopes in recombinant tau by $\mathrm{cdc} 2 /$ cyclin B. $A,{ }^{32} \mathrm{P}$ incorporation. Histone $\mathrm{H} 1$ and tau were incubated with the indicated proline-directed kinases. Bottom panels (i.e., gel) for each substrate show Coomassie blue staining of the protein in the gel, and the top panels (i.e., autorad) show the corresponding autoradiograms. Equivalent amounts of ${ }^{32} \mathrm{P}$ were incorporated into $\mathrm{H} 1$ after incubation with the indicated kinases. This was also the case with tau as substrate, except that higher amounts of ${ }^{32} \mathrm{P}$ incorporation were observed with MAPK. The positions of molecular weight (MW) markers in kilodaltons are shown on the left of each panel. $B$, Tau immunoreactivity. Replicate panels of tau protein phosphorylated with MAPK, cdc2/cyclin B, cdk5, or GSK-3, respectively, were stained with the TG/MC and PHF-1 antibodies as indicated on the left of each panel. Whereas all the kinases produced the PHF-1 phospho-epitope in tau, only cdc2/cyclin B produced the mitotic TG/MC epitopes. The position of the $70 \mathrm{kDa}$ MW marker is shown on the left of each panel.

abundant cdk5, generated the TG/MC phospho-epitopes (Fig. $8 B)$. Thus, whereas the nonmitotic PHF-1 phospho-epitope is produced by all proline-directed kinases, the TG/MC mitotic phospho-epitopes in tau are generated preferentially by $\operatorname{cdc} 2 /$ cyclin B.

\section{DISCUSSION}

Although it is well established that adult brain neurons are postmitotic (Rakic, 1985) and lack mitotic kinase activity (Hayes et al., 1991; Okano et al., 1993; Tsai et al., 1993; Buchkovich and Ziff, 1995; Dobashi et al., 1995), our studies demonstrate the presence of the two components of a functional mitotic kinase complex, catalytically active cdc2 and cyclin B1, in terminally differentiated neurons of $\mathrm{AD}$ brain. The proteins co-localize to diseased neurons containing phosphoproteins, the accumulation of which is a harbinger for NFT formation and neuronal death. This reexpression of cdc2 and cyclin B1 in neurons is not observed in elderly normal human or adult mouse brain, but only in $\mathrm{AD}$ neurons vulnerable to NFT, a human-specific lesion. Detection of these mitotic regulatory proteins in neurons provides a basis for advancing the hypothesis that a mitotic mechanism may be operative in AD. Two additional lines of evidence in these studies support the 
above idea. PHF-tau forms a physiological complex with mitotic kinase from $\mathrm{AD}$ brain and is phosphorylated by the bound kinase in vitro; the mitotic $\mathrm{TG} / \mathrm{MC}$ phosphoepitopes are created preferentially in tau by cdc $2 /$ cyclin $\mathrm{B}$, but not other protein kinases recognizing similar canonical phosphorylation sites.

Visualization of cdc2 in NFT-bearing neurons was accomplished with three antibodies recognizing independent primary sequence epitopes in human cdc 2 and, more importantly, having no cross-reactivity with the neuronal cdk5. This specificity was supported further by immunoblot data demonstrating the $34 \mathrm{kDa}$ cdc2 kinase in p13suc1 precipitates from brain. Although previous studies have hinted at the presence of cdc2 in NFT (Ledesma et al., 1992; Wood et al., 1993; Pei et al., 1994), interpretation of the results was difficult because cross-reactivity with the homologous cdk5 kinase was not established. A novel cdc2-like kinase lacking PSTAIRE immunoreactivity and associated with PHF in AD was reported recently by Liu et al. (1995). It is unlikely that the neuronal kinase detected in our studies is similar to this cdc2-like kinase, given the staining of NFT-containing neurons with the PSTAIRE antibody and its reactivity with cdc2 in $\mathrm{p} 13$ suc1 precipitates (data not shown). Instead, our data with the three cdc2 antibodies suggest the presence of authentic cdc2 in neurons. Moreover, based on the intense labeling of NFT-bearing neurons and neuritic plaques with the active kinase antibody, it is deduced that cdc 2 is in a catalytically active state in AD neurons. Additional sites of post-translational modification are important for cdc2 activation (for review, see Coleman and Dunphy, 1994) and need to be investigated in additional studies. At the level of regulation by cyclin, the co-localization of cyclin $\mathrm{B} 1$ with active cdc2 in neurons satisfies the requirements for optimal activation of the kinase. In $\mathrm{M}$ phase, translocation of cyclin $\mathrm{B}$ into the nucleus is an additional prerequisite for activation of cdc2 (Pines and Hunter, 1991). Although nuclear cyclin B1 was predominant in some $\mathrm{AD}$ cases, active cdc 2 and mitotic phospho-epitopes were located in the cytoplasm. A reasonable explanation for this discrepancy, in light of the observed sensitivity of cyclin B1 to postmortem autolysis, is that the concentration of cyclin in the nucleus is high enough to be detected even after much of the cytosolic cyclin is degraded. It is also possible that the nuclear membrane confers some protection from postmortem degradation by cytoplasmic proteases. The appearance of cyclin B1 without cdc2 or mitotic phospho-epitopes in some neurons of $\mathrm{AD}$, and in some normal cases, suggests that neuronal expression of the cyclin precedes expression and post-translational activation of $\operatorname{cdc} 2$.

Of significance is the observation that the majority of cdc2positive NFT were intraneuronal rather than extraneuronal. A similar observation was made previously with the MPM-2 antibody in that MPM-2-reactive phospho-epitopes were found primarily in intraneuronal NFT (Vincent et al., 1996). Abnormal fibrils first appear in the cytoplasm of neurons and eventually fill the entire neuronal cell body, leaving behind an insoluble extracellular NFT after the neuron dies (Terry et al., 1994). The selective staining of intracellular NFT with cdc2 and MPM-2 antibodies is therefore suggestive of a role for mitotic kinase in early stages of neurofibrillary pathology. This may explain why these antibodies stain fewer NFT than are visualized with TG-3, an antibody that detects both early and late NFT. Another peculiarity of the MPM-2 and cdc2 antibodies is their sparse reactivity with dystrophic neurites. In part, this may be attributable to a differential sensitivity of neuritic components to fixation, because Liu et al. (1995) noted weaker staining of neuritic processes in tissue fixed with paraformaldehyde in comparison with Bouin's fixative. Alternatively, it may reflect a transient pathological state of the dystrophic neurite.

The predominant staining of NFT-bearing neurons with the active kinase antibody in most cases of $\mathrm{AD}$ argues that a significant proportion of the active cde2 in $\mathrm{AD}$ brain is of neuronal origin. This idea is supported further by the reciprocal results with the inactive kinase antibody, which showed ample immunoreactivity in endothelial and glial cells, but did not react with neurons. Overall, the sparse blood vessels, astrocytes, and glial nuclei containing active cdc2 and cyclin reflect a relatively low level of proliferating non-neuronal cells in brain. The contribution of non-neuronal mitotic kinase to the increase in mitotic kinase activity in AD p13suc1 preparations is therefore likely to be minimal. On the other hand, inactive cdc2 and cyclin from non-neuronal sources may contribute significantly to basal levels of the proteins in brain extracts, thereby diminishing the magnitude of the neuronal increment in AD. This problem may have been exacerbated by the sampling of tissue for biochemical analysis, because the distribution of cdc2-positive NFT within a given brain region was not homogenous. Thus, although modest increases in kinase and cyclin levels were detected in AD extracts, they did not seem to parallel the more striking increases visualized at the immunocytochemical level. This issue may be particularly pertinent in cases of $\mathrm{AD}$ and normal brain that exhibited clusters of cdc2/cyclin B1-positive, but active kinase-negative glial cells. Some of these glial clusters resembled reactive glial cells, but there was no significant increase in staining of such clusters in AD, despite obvious increases in gliosis in some cases. Because of these considerations, detailed quantitative analysis using micro-dissected tissues would be more appropriate. Nevertheless, the preponderance of our present data supports an increase in amount and activity of the cdc2 mitotic kinase in $\mathrm{AD}$ neurons.

Errant activation of cdc2 does not imply that neurons undergo mitosis. Mitotic figures have never been observed in neurons of AD or normal brain, perhaps because differentiated neurons respond to elevated mitotic kinase activity by undergoing neurodegeneration, rather than cytokinesis. In a number of experimental paradigms with non-neuronal cells, premature activation of cdc2 triggers a "mitotic catastrophe" leading to apoptosis (Steinmann et al., 1991; Ucker et al., 1991; Meikrantz et al., 1994; Shi et al., 1994; Shimizu et al., 1995). The work of Greene and colleagues (Ferrari and Greene, 1994; Farinelli and Greene, 1996; Park et al., 1996) has suggested that cdc2 and other cell-cycle proteins may also participate in apoptosis of differentiated neuronal cells. At least some (Su et al., 1994; Dragunow et al., 1995; Lassmann et al., 1995; Smale et al., 1995), but certainly not all (Migheli et al., 1994; for review, see Dickson et al., 1995), neurons of AD brain exhibit features of apoptotic death. Recently, the mouse homolog (ALG3) of an identified familial AD gene (STM2) encoding for presenilin 2 was shown to rescue $\mathrm{T}$ lymphocytes from $\mathrm{T}$ cell receptor- and Fas-induced apoptosis (Vito et al., 1996). Thus, apoptosis may be a feasible mechanism of death for some vulnerable neurons in AD. On the other hand, Heinz (1993) has speculated that neurons degenerate by a mechanism akin to that of neoplastic transformation. This speculation was based on evidence that the same genes, when induced in dividing cells lead to clonal expansion and transformation in terminally differentiated cells, result in clonal elimination and neurodegenerative disease 
(Clarke et al., 1992; Feddersen et al., 1992; Jacks et al., 1992). In other words, proteins that have vital roles in cell-cycle control and are typically dormant in terminally differentiated neurons may serve as critical regulators of neuronal death. Our data support the idea that aberrant expression and activation of mitotic kinase participates in neurodegeneration in AD. Whether this mitotic activation is associated with neoplastic transformation or apoptosis, or with an independent mechanism, remains to be elucidated in additional experiments. Evaluating the status of specific markers for each of these processes in $\mathrm{AD}$ brain would be required to define the pathway leading to neuronal death in AD.

Based on this discussion and the induction of cdc 2 and cyclin $\mathrm{B} 1$ in $\mathrm{AD}$ neurons, it appears that neuronal death in $\mathrm{AD}$ proceeds via an active, rather than passive, mechanism, with NFT constituting a byproduct of the destructive cascade. Two M-phase regulators of cdc2, the wee- 1 tyrosine kinase and the cdc25 phosphatase (for review, see Coleman and Dunphy, 1994) are now proven MPM-2 phosphoproteins (Kuang et al., 1994; Mueller et al., 1995). It is reasonable to speculate that these proteins are candidate MPM-2 antigens in NFTcontaining neurons as well. Studies of these and other upstream regulators and downstream effectors of cdc2/cyclin B1 in brain would help delineate the mechanism involved in neurofibrillary pathology and neurodegeneration in AD.

\section{REFERENCES}

Azzi L, Meijer L, Ostvold A-C, Lew J, Wang JH (1994) Purification of a 15 kDa cdk4- and cdk5- binding protein. J Biol Chem 269:13279-13288.

Braak H, Braak E (1991) Neuropathologic staging of Alzheimer-related changes. Acta Neuropathol 82:239-259.

Brizuela L, Draetta G, Beach D (1987) P13suc1 acts in the fission yeast cell division cycle as a component of the $\mathrm{p} 34 \mathrm{cdc} 2$ protein kinase. EMBO J 6:3507-3514.

Buchkovich KJ, Ziff EB (1995) Nerve growth factor regulates the expression and activity of p33cdk2 and p34 cdc2 kinases in PC12 Pheochromocytoma cells. Mol Biol Cell 5:1225-1241.

Clarke AR, Maandag ER, van Roon M, van der Lugt NM, van der Valk M, Hooper ML, Berns A, te Riele H (1992) Requirement for a functional Rb-1 gene in murine development. Nature, 359:270-271.

Coleman TR, Dunphy WG (1994) Cdc2 regulatory factors. Curr Biol 6:877-882.

Dickson DW (1995) Apoptosis in the brain. Am J Pathol 146:1040-1044.

Dobashi Y, Kudoh T, Matsumine A, Totoshima K, Akiyama T (1995) Constitutive overexpression of cdk2 inhibits neuronal differentiation of rat pheochromocytoma PC12 cells. J Biol Chem 270:23031-23037.

Draetta G, Beach D (1988) Activation of cdc2 protein kinase during mitosis in human cells: cell cycle-dependent phosphorylation and subunit rearrangement. Cell 54:17-25.

Dragunow M, Faull RL, Lawlor P, Beilharz EJ, Singleton K, Walker EB, Mee E (1995) In situ evidence for DNA fragmentation in Huntington's disease striatum and Alzheimer's disease temporal lobes. NeuroReport 6:1053-1057.

Drewes G, Lichtenberg-Kraag B, Doring F, Mandelkow E-M, Biernat J, Goris J, Doree M, Mandelkow E (1992) Mitogen activated protein (MAP) kinase transforms tau into an Alzheimer-like state. EMBO J 11:2131-2138.

Feddersen RM, Ehlenfeldt R, Yunis WS, Clark HB, Orr HT (1992) Disrupted cerebellar cortical development and progressive degeneration of Purkinje cells in SV40 T antigen transgenic mice. Neuron 9:955-966.

Farinelli SE, Greene LA (1996) Cell cycle blockers mimosine, ciclopirox, and desferoxamine prevent the death of PC12 cell and postmitotic sympathetic neurons after removal of trophic support. J Neurosci $16: 1150-1162$.

Ferrari G, Greene LA (1994) Proliferative inhibition by dominantnegative Ras rescues naive and neuronally differentiated PC12 cells from apoptotic death. EMBO J 13:5922-5928.

Galaktionov K, Jesus C, Beach D (1995) Raf1 interaction with cdc25 phosphatase ties mitogenic signal transduction to cell cycle activation Genes Dev 9:1046-1058.

Goedert M, Spillanti MG, Cairns NJ, Crowther RA (1992) Tau proteins of Alzheimer paired helical filaments: abnormal phosphorylation of all six isoforms. Neuron 8:159-168.

Greenberg SG, Davies P (1990) A preparation of Alzheimer paired helical filaments amenable to conventional biochemical analysis. Proc Natl Acad Sci USA 87:5827-5831.

Hall FL, Vulliet PR (1991) Proline-directed protein phosphorylation and cell cycle regulation. Curr Opin Cell Biol 3:176-184.

Hayes TE, Valtz NLM, McKay RDG (1991) Downregulation of cdc2 upon terminal differentiation of neurons. New Biol 3:259-269.

Heinz N (1993) Cell death and the cell cycle: a relationship between transformation and neurodegeneration? Trends Pharmacol 18:157-159.

Hunter T (1995) Protein kinases and phosphatases: the yin and yang of protein phosphorylation and signalling. Cell 80:225-236.

Jacks T, Fazeli A, Schmitt EM, Bronson RT, Goodell MA, Weinberg RA (1992) Effects of an Rb mutation in the mouse. Nature 359:270-271.

Kuang J, Ashorn CL, Gonzalez-Kuyvenhoven M, Penkala JE (1994) Cdc25 is one of the MPM-2 antigens involved in the activation of maturation-promoting factor. Mol Biol Cell 5:135-145.

Lassmann H, Bancher C, Breitschopf H, Wegiel J, Bobinski M, Jellinger K, Wisniewski HM (1995) Cell death in Alzheimer's disease evaluated by DNA fragmentation in situ. Acta Neuropathol 89:35-41.

Ledesma MD, Correas I, Avila J, Diaz-Nido J (1992) Implication of brain cdc2 and MAP2 kinases in the phosphorylation of tau protein in Alzheimer's disease. FEBS Lett 308:218-224.

Lew J, Wang JH (1995) Neuronal cdc2-like kinase. Trends Pharmacol 20:33-37.

Liu W-K, Williams RT, Hall FL, Dickson DW, Yen S-H (1995) Detection of a cdc2-related kinase associated with Alzheimer paired helical filaments. Am J Pathol 146:228-238.

Mandelkow E-M, Drewes G, Biernat J, Gustke N, Van Lint J, Vandenheede R, Mandelkow E (1992) Glycogen synthase kinase-3 and the Alzheimer-like state of microtubule associated protein tau. FEBS Lett 314:314-321.

Meikrantz W, Gisselbracht S, Tam SW, Schlegel R (1994) Activation of cyclin A-dependent protein kinases during apoptosis. Proc Natl Acad Sci USA 91:3754-3758.

Meyerson M, Enders GH, Wu C-L, Su L-K, Gorka C, Nelson C, Harlow E, Tsai L-H (1992) A family of human cdc2-related kinases. EMBO J 11:2909-2917.

Migheli A, Cavalla P, Marino S, Schiffer D (1994) A study of apoptosis in normal and pathologic nervous tissue after in situ labeling of DNA strand breaks. J Neuropathol Exp Neurol 53:606-616.

Mueller PR, Coleman TR, Dunphy WG (1995) Cell cycle regulation of a Xenopus Wee1-like kinase. Mol Biol Cell 6:119-134.

Nigg EA (1993) Cellular substrates of p34cdc2 and its companion cyclindependent kinases. Trends Cell Biol 3:296-301.

Okano H, Pfaff DW, Gibbs RB (1993) RB and cdc2 expression in brain: correlations with ${ }^{3} \mathrm{H}$-thymidine incorporation and neurogenesis. J Neurosci 13:2930-2938.

Otvos Jr L, Feiner L, Lang E, Szendrei GI, Goedert M, Lee VM (1994) Monoclonal antibody PHF-1 recognizes tau protein phosphorylated at serine residues 396 and 404. J Neurosci Res 39:669-673.

Park DS, Farinelli SE, Greene LA (1996) Inhibitors of cyclin-dependent kinases promote survival of post-mitotic neuronally differentiated PC12 cells and sympathetic neurons. J Biol Chem 271:8161-8169.

Paudel HK, Lew J, Ali Z, Wang JH (1993) Brain proline-directed kinase phosphorylates tau on sites that are abnormally phosphorylated in tau associated with Alzheimer's paired helical filaments. J Biol Chem 268:23512-23518.

Pei J-J, Sersen E, Iqbal K, Grundke-Iqbal I (1994) Expression of protein phosphatases (PP-1, PP2A, PP2-B, and PTP-1B) and protein kinases (MAP kinase and p34cdc2) in the hippocampus of patients with Alzheimer disease and normal aged individuals. Brain Res 655:70-76.

Pines J, Hunter T (1991) Human cyclins A and B1 are differentially located in the cell and undergo cell cycle-dependent nuclear transport. J Cell Biol 115:1-17.

Rakic P (1985) DNA synthesis and cell division in the adult primate brain. Ann NY Acad Sci 457:193-211.

Samiei M, Daya-Makin M, Clarke-Lewis I, Pelech SL (1991) Plateletactivating factor- and thrombin-induced stimulation of p34cdc2-cyclin histone H1 kinase activity in platelets. J Biol Chem 266:14889-14892.

Shi L, Nishioka WK, Th'ng JP, Bradbury EM, Litchfield DW, Greenberg 
AH (1994) Premature p34cdc2 activation required for apoptosis. Science 263:1143-1145.

Shimizu T, O'Connor PM, Kohn KW, Pommier Y (1995) Unscheduled activation of cyclin $\mathrm{B} 1 / \mathrm{cdc} 2$ kinase in human promyelocytic leukemia cell line HL60 cells undergoing apoptosis induced by DNA damage. Cancer Res 55:228-231.

Smale G, Nichols NR, Brady DR, Finch CE, Horton WE (1995) Evidence for apoptotic cell death in Alzheimer's disease. Exp Neurol 133:225-230.

Solomon MJ, Glotzer M, Lee TH, Phillippe M, Kirschner M (1990) Cyclin activation of p34cdc2. Cell 63:1013-1024.

Steinmann KE, Belinsky GS, Lee D, Schlegel R (1991) Chemically induced premature mitosis: differential response in rodent and human cells and the relationship to cyclin B synthesis and p34cdc2/cyclin B complex formation. Proc Natl Acad Sci USA 88:6843-6847.

$\mathrm{Su} \mathrm{JH}$, Anderson AJ, Cummings BJ, Cotman CW (1994) Immunohistochemical evidence for apoptosis in Alzheimer's disease. NeuroReport 5:2529-2533.

Terry RD, Masliah E, Hansen LA (1994) Structural basis of the cognitive alterations in Alzheimer's disease. In Alzheimer disease (Terry RD, Katzman R, Bick K, eds), pp 179-196. New York: Raven.

Tournier S, Raynaud F, Gerbaud P, Lohmann SM, Doree M, Evian-Brion
D (1991) Association of type II cAMP-dependent protein kinase with p34cdc2 protein kinase in human fibroblasts. $J$ Biol Chem 266:19018-19022.

Trojanowski TQ, Schmidt ML, Shin RW, Bramblett GT, Rao D, Lee VM (1993) Altered tau and neurofilament proteins in neuro-degenerative disease: diagnostic implication for Alzheimer's disease and Lewy body dementias. Brain Pathol 3:45-54.

Tsai L-H, Takahashi T, Caviness VS, Harlow E (1993) Activity and expression pattern of cyclin-dependent kinase 5 in the embryonic mouse nervous system. Development 119:1029-1040.

Ucker DS (1991) Death by suicide: one way to go in mammalian cellular development. New Biol 3:103-109.

Vincent I, Rosado M, Davies P (1996) Mitotic mechanisms in Alzheimer's disease? J Cell Biol 132:413-425.

Vito P, Lacana E, D'Adamio L (1996) Interfering with apoptosis: $\mathrm{Ca}^{2+}$ binding protein ALG2 and Alzheimer's disease gene ALG-3. Science 271:521-525.

Watanabe N, Broome M, Hunter T (1995) Regulation of the human wee1hu CDK tyrosine 15-kinase during the cell cycle. EMBO J 14:1878-1891.

Wood JG, Lu Q, Reich C, Zinsmeister P (1993) Proline-directed kinase systems in Alzheimer's disease pathology. Neurosci Lett 156:83-86. 